\title{
Should Hypopharynx Cancer Continue to be Included in "Multi- Head and Neck" Trials within the RTOG?
}

\author{
R. Den \\ Thomas Jefferson University Hospitals \\ Q. Zhang \\ RTOG Statistical Center \\ D. Cognetti \\ Thomas Jefferson University Hospitals \\ M. Machtay \\ Case Western Reserve University School of Medicine \\ J.S. Cooper \\ Maimonides Medical Center \\ Follow this and additional works at: https://jdc.jefferson.edu/bodinejournal \\ Part of the Oncology Commons

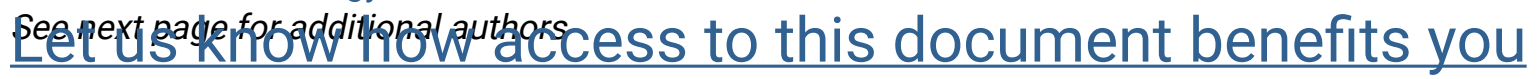

\section{Recommended Citation}

Den, R.; Zhang, Q.; Cognetti, D.; Machtay, M.; Cooper, J. S.; Garden, A. S.; Jones, C. U.; Yom, S.; and Ang, K. K. (2010) "Should Hypopharynx Cancer Continue to be Included in "Multi-Head and Neck" Trials within the RTOG?," Bodine Journal: Vol. 3 : Iss. 1 , Article 27.

DOI: https://doi.org/10.29046/TBJ.003.1.026

Available at: https://jdc.jefferson.edu/bodinejournal/vol3/iss1/27

This Article is brought to you for free and open access by the Jefferson Digital Commons. The Jefferson Digital Commons is a service of Thomas Jefferson University's Center for Teaching and Learning (CTL). The Commons is a showcase for Jefferson books and journals, peer-reviewed scholarly publications, unique historical collections from the University archives, and teaching tools. The Jefferson Digital Commons allows researchers and interested readers anywhere in the world to learn about and keep up to date with Jefferson scholarship. This article has been accepted for inclusion in Bodine Journal by an authorized administrator of the Jefferson Digital Commons. For more information, please contact: JeffersonDigitalCommons@jefferson.edu. 
Should Hypopharynx Cancer Continue to be Included in "Multi-Head and Neck" Trials within the RTOG?

\section{Authors}

R. Den, Q. Zhang, D. Cognetti, M. Machtay, J. S. Cooper, A. S. Garden, C. U. Jones, S. Yom, and K. K. Ang 


\section{Should Hypopharynx Cancer Continue to be Included in "Multi-Head and Neck" Trials within the RTOG?}

Den, R., ${ }^{1}$ Zhang, Q., ${ }^{2}$ Cognetti, D., ${ }^{3}$ Machtay, M., ${ }^{4}$ Cooper, J.S., ${ }^{5}$ Garden, A.S., ${ }^{6}$ Jones, C.U., ${ }^{7}$ Yom, S., ${ }^{8}$ Ang, K.K. ${ }^{6}$

${ }^{1}$ Department of Radiation Oncology, Thomas Jefferson University and Hospitals, Philadelphia, PA

${ }^{2}$ RTOG Statistical Center, Philadelphia, PA

${ }^{3}$ Department of Otolaryngology, Thomas Jefferson University and Hospitals, Philadelphia, PA

${ }^{4}$ Case Western Reserve University School of Medicine, Cleveland, $\mathrm{OH}$

${ }^{5}$ Maimonides Medical Center, Brooklyn, NY

6University of Texas M.D. Anderson Cancer Center, Houston, TX

${ }^{7}$ Radiological Associates to Sacramento, Sacramento, CA

¿University of California San Francisco, San Francisco, CA.

\section{Purpose/Objective(s)}

It is becoming increasingly evident that the behavior of cancers from different subsites of the head and neck varies greatly despite similar histologic appearance. As current head and neck trials are focusing more on a risk-based approach, it is unclear into which trials patients with hypopharyngeal primaries (HP) should be included. Thus, we undertook to examine whether patients with HP perform as well as oropharyngeal primaries (OP) in the definitive setting and whether HP perform as well as larynx primaries (LX) in the post-operative setting in the multi-institutional setting.

\section{Materials/Methods}

We investigated two situations. First, in the definitive setting of RTOG 9003 (RT: 4 regimens), we limited our analysis to those OP cancer patients with $>10$ year smoking history to minimize the potential confounder of HPV positivity, a known good prognostic marker. In the postoperative setting of RTOG 9501 (RT vs. CRT) we compared HP cancer vs. LX cancer. The effects of primary site on disease-free and overall survival (DFS, OS) and pattern of failure (local regional control, LC, and distant metastases, DM) were evaluated using Cox proportional hazards models adjusted for primary site, $\mathrm{T}$ stage, $\mathrm{N}$ stage, treatment, and KPS. Logistic regression was used to model the probability of Grade 3-5 late toxicity ( $>90$ days from start of radiation therapy) in HP patients as compared to other sites.

\section{Results}

A total of $108 \mathrm{HP}$ and 605 OP were analyzed from RTOG 9003. In RTOG 9501, 40 HP and 86 LX primaries were analyzed.

In the definitive setting, when limiting OP to those with $>10$ packyears, there is some indication that HP has worse OS [HR 1.14 (0.911.43)] and DFS [HR 1.2 (0.96-1.5]. There was no indication of worse LC or DM rate.
In the postoperative setting, HP did not have worse outcomes to patients with LX in terms of OS [HR 1.09 (0.69-1.7)], DFS [HR 1.01 (0.65-1.57)], LC [HR 1.15 (0.53-2.5)], and DM [HR 1.3 (0.75-2.26)].

There is no indication that HP patients have more Grade 3-5 late toxicity than other sites in either the postoperative or definitive setting.

\section{Conclusion}

Patients with primary HP carcinoma have worse OS, and DFS, in the definitive setting in comparison to OP patients with greater than 10 year smoking history. In the postoperative setting, patients with HP have similar outcomes to LX patients. This suggests that HP patients do not require separate trials, but consideration should be given to stratification by disease site in future multi-H\&N trials.

This project was supported by RTOG grant U10 CA21661, and CCOP grant U10 CA37422 from the National Cancer Institute (NCI). 